\title{
La plataforma Dark.Netflix como ejemplo de estrategia de amplificación de la transficcionalidad transmedia
}

\section{The Dark.Netflix platform as an example of transmedia transfictionality amplification strategy}

\author{
Rodríguez Fidalgo, M. I., Paíno Ambrosio, A. y Ruiz Paz, Y. ${ }^{1}$ \\ Recibido: 04-05-2021 - Aceptado: 05-08-2021 \\ https://doi.org/10.26441/RC20.2-2021-A18
}

RESUMEN: Este estudio analiza la plataforma de la serie Dark, una de las últimas apuestas de Netflix para ofrecer contenidos adicionales a los fans de la ficción. Mediante el empleo de la herramienta metodológica del découpage interactivo se profundiza en los distintos elementos narrativos que han permitido elaborar la experiencia interactiva. Se concluye que Dark.Netflix propone una estrategia de amplificación para llevar a cabo la transficción transmedia en el soporte digital que genera un nuevo diálogo narrativo interactivo con los usuarios/seguidores.

Palabras clave: Netflix; narrativa interactiva; serie; expansión hipertextual; transmedia.

\begin{abstract}
This study analyzes the Dark series platform, one of Netflix's latest bets to offer additional content to fiction fans. By using the methodological tool of interactive decoupage, this study goes deeper into the different narrative elements that have allowed the elaboration of the interactive experience. It is concluded that Dark.Netflix proposes an amplification strategy to carry out the transmedia transfiction in the digital support that generates a new interactive narrative dialogue with their users/followers.
\end{abstract}

Keywords: Netflix; interactive storytelling; series; hypertext expansión; transmedia.

\footnotetext{
${ }^{1} \mathbf{M}^{\mathrm{a}}$ Isabel Rodríguez Fidalgo es Doctora por la Universidad de Salamanca y profesora en el Departamento de Sociología y Comunicación, dentro del área de Comunicación Audiovisual y Publicidad, de la Facultad de Ciencias Sociales. Imparte docencia en el Grado de Comunicación y Creación Audiovisual y en el Máster de Servicios Públicos y Políticas Sociales de dicha Facultad. Sus líneas de investigación giran en torno al diseño y construcción de los nuevos contenidos mediáticos multipantalla, nuevas narrativas hipermedia-transmedia, documental interactivo y periodismo inmersivo. mrfidalgo@usal.es, http://orcid.org/0000-0001-5167-0272

Adriana Paíno Ambrosio es Doctora en Ciencias Sociales por la Universidad de Salamanca y profesora en la Facultad de Ciencias Sociales de la Universidad Europea Miguel de Cervantes, impartiendo docencia en diversos grados. Sus líneas de investigación se centran en el estudio de los nuevos formatos periodísticos en el escenario digital, los documentales interactivos, el ciberperiodismo, el periodismo inmersivo y las narrativas transmedia de ficción y de no ficción. apaino@uemc.es, https://orcid.org/0000-0003-3817-6071

Yanira Ruiz Paz es Doctora en Ciencias Sociales por la Universidad de Salamanca y Máster en Servicios Públicos y Políticas Sociales por la misma universidad. Además, es Ingeniera en Sistemas Computacionales por el Instituto Tecnológico de Colima (México). Sus líneas de investigación se centran en la comunicación política y las redes sociales. yaniraruiz_paz@usal.es, https://orcid.org/0000-0002-1848-5662
} 


\section{Introducción}

La industria audiovisual evoluciona al compás del imparable avance tecnológico originando cambios profundos vinculados a la creación y el consumo mediático. En este contexto, los profesionales se enfrentan a un nuevo tipo de espectador que ha dejado atrás una búsqueda de entretenimiento pautada por las carteleras de cine y las parrillas diarias de televisión, para pasar a consumir contenidos audiovisuales que él mismo selecciona y visualiza en el momento y lugar que decida (Capapé, 2020; González y Fernández, 2019). La distribución de contenidos a la carta y a través de un sistema multipantalla ha trasladado a un segundo plano el consumo lineal y síncrono (Alcolea, 2017). Dicha realidad ha sido asumida rápidamente por la industria a nivel mundial dando lugar, en los últimos años, a la aparición de grandes plataformas de distribución de contenidos audiovisuales como Netflix, que responden a las características descritas anteriormente y que caracterizan al escenario audiovisual actual. Uno de sus contenidos estrella son, sin duda, las series de ficción en torno a las cuales se está desarrollando una nueva cultura del entretenimiento que pone el foco, ahora más que nunca, sobre los espectadores/seguidores; es decir, el concepto de fidelización de las audiencias evoluciona hacia una dimensión que potencia un espectador que no sólo esté "enganchado" al consumo de dichas series, sino que busca además un consumo personalizado dentro de estas plataformas. Esto se produce gracias al uso del big data, relacionado directamente con el diseño algorítmico en el que están basadas y que permite, cada vez más, ofrecer al usuario-espectador un sistema más refinado en lo que a la oferta de contenidos se refiere, relacionado con sus gustos y preferencias previas (Carrillo, 2018). Dentro de las últimas novedades que están introduciendo este tipo de plataformas destacan el salto a la producción de contenido original, convirtiéndose en un sello de identidad y fidelización para sus suscriptores, y la creación de contenidos adicionales distribuidos por otros soportes digitales y vinculados a las series que distribuyen.

Teniendo en cuenta dichos aspectos surge la investigación que aquí se plantea, que centra su objeto de estudio en la plataforma que Netflix ha creado en torno a Dark (2017-2020), una de las series que ha acumulado mayor éxito a nivel mundial en los últimos años, que cuenta con tres temporadas emitidas. Este estudio se aborda desde una perspectiva novedosa que implica profundizar en la estrategia de amplificación llevada a cabo en la mencionada plataforma, en adelante Dark.Netflix, para analizar en qué medida este tipo de contenidos adicionales construyen la transficción transmedia de la serie y permiten hablar de un nuevo diálogo narrativo interactivo.

\section{Marco Teórico}

\subsection{Una nueva forma de consumir contenidos audiovisuales: el caso de Netflix}

Los servicios de vídeo bajo demanda por suscripción o SVOD han cambiado los patrones de consumo de televisión apostando por un modelo en el que prima la autonomía del espectador (Raya, Sánchez-Labella y Durán, 2018). De esta manera se produce un cambio significativo respecto al modelo televisivo tradicional, que queda todavía más evidenciado cuando se trata de contenido de video serializado (Merikivi et al. 2019). El consumo programado o appointed viewing implica que el espectador debía esperar a la emisión del siguiente capítulo, pero los servicios de suscripción bajo demanda conceden al usuario la libertad de decidir cuándo quiere ver el episodio o la temporada de la serie al completo una vez que está accesible en la plataforma (Billard, 2019; Susanno, Phedra y Murwani, 2019). Si bien es cierto, mientras que algunas series se pueden visualizar de manera íntegra (todos los capítulos de una temporada), otras en cambio ofrecen a sus suscriptores el estreno de un capítulo cada semana, como así sucede en el modelo televisivo (generalmente son aquellas producciones que se distribuyen por un sistema multiplataforma). Por otra parte, estos servicios facilitan el acceso desde diferentes soportes (TV, ordenadores, smartphones y tablets) lo que dota al usuario de completa libertad -en lo que a 
dispositivos se refiere- a la hora de acceder a los contenidos audiovisuales. Esta realidad, por lo tanto, marca nuevos rumbos dentro del escenario de convergencia mediática apuntado hace años por autores como Jenkins (2008) o Scolari (2009) en cuanto a distribución y consumo (Ellingsen, 2014). En este sentido, como sostiene Heredia, "hace veinte años, por ejemplo, una película se demoraba varios años en llegar a la televisión abierta y los sistemas de streaming no se consideraban siquiera una ventana de exhibición" (2016: 279-280). En la actualidad, los lanzamientos de los últimos estrenos de películas y series a través de las grandes Over The Top (OTT) comienzan a consolidar nuevas formas de hacer negocio dentro de los parámetros por los que viene marcado ahora el entretenimiento audiovisual basados en un modelo por suscripción (Lad, Butala y Bide, 2020). Entre las grandes OTT se encuentran Netflix, HBO, Disney+ o Amazon Prime Video, entre otras, que van a diferenciarse especialmente en el volumen de su catálogo y en la estructura de pago. La popularidad de estas plataformas aumenta entre el público más joven produciéndose un fenómeno conocido como binge watching o consumo en maratón (Castro et al. 2019). A este respecto, refiriéndose al caso específico de Netflix, autores como Matrix (2014) añaden:

In the popular press, binge viewing and Netflix are becoming synonymous, especially for young viewers, including "screenagers." Of course, not all millennials were "born digital" or have access to these services. Those who do, however, increasingly are not content to abide by traditional weekly and seasonal programming schedules: connected Gen Y (currently aged eighteen to thirty-four) and Gen Z (young people born after 2005) with access to these services are practising new television viewing styles using a variety of digital technologies, particularly subscription-based video on demand (VOD or SVOD) via Netflix. (Matrix, 2014: 120)

Profundizando en las particularidades que presenta este gigante audiovisual es necesario aludir a su estrategia de negocio, que determina el posicionamiento de la marca Netflix dentro del mercado audiovisual. Como indica Mayorga, este pivota en tres aspectos: "marca global, desarrollo tecnológico... y protagonismo absoluto de los contenidos" (2019: 238). Precisamente, dentro de este último aspecto, hay que destacar sin duda el catálogo de producción propia con el que cuenta Netflix (películas, ficción seriada, documentales, etc.), que viene caracterizado por un amplio abanico de idiomas originales y subtítulos. Esta cuestión, junto con su apuesta por las coproducciones, imprime a la marca un claro carácter de internacionalización (Hidalgo, 2020; Lobato, 2019).

Desde hace varios años Netflix ha comenzado a explorar esta vía de producción propia de contenidos, destacando aquí por sus elevadas inversiones presupuestarias en relación a lo que se venía haciendo en otras producciones de este tipo (Matisse, 2013; Goudmand, 2020). El modelo de negocio funcionó y prueba de ello es el gran volumen de títulos de éxito que se han estrenado en esta plataforma hasta la actualidad, lo que ha dado lugar a un importante corpus dentro de la literatura académica. Así, se pueden citar contribuciones que analizan series como Orange Is the New Black (DeCarvalho y Cox, 2016; Smith, 2015), Black Mirror (Elnahla, 2019; Hills, 2019), Stranger Things (Barnwell, 2020; Carvalho, Barcelos y Dias, 2017), Narcos (Amaya y Trujillo, 2018; Rocha, 2018), Sense8 (Ruíz y Bustos, 2020) o Mindhunter (Naranjo y Fernández Ramírez, 2020), entre otros. Uno de los títulos que ha despertado un gran interés dentro de esta plataforma a nivel mundial es la serie Dark. Según los datos de Parrot Analytics, los días posteriores a su estreno, esta serie logró alcanzar datos de audiencia muy superiores a otras ficciones europeas de Netflix, como Las chicas del cable, Suburra o Marseille (Wyche, 2018).

\subsection{La serie Dark y la propuesta de nuevos contenidos para sus seguidores}

Creada por Baran bo Odar y Jantje Friese y estrenada en el año 2017, Dark es la primera serie original de Netflix en idioma alemán. En sus tres temporadas y 26 episodios, la ficción sigue las consecuencias de la desaparición de un niño -Mikkel Nielsen- en la pequeña ciudad ficticia de Winden. Lo que en principio parece una serie de temática policial que trata de descubrir los misterios que se 
esconden tras este suceso, terminará convirtiéndose en una serie distópica, que incluye viajes en el tiempo y dimensiones alternativas que afectan a todos los habitantes de Winden. Cada capítulo tiene una duración diferente, entre 45 y 73 minutos, como se puede observar en la tabla 1.

Tabla 1. Distribución de capítulos por temporada emitida

\begin{tabular}{|c|c|c|c|c|c|}
\hline \multicolumn{2}{|c|}{ Temporada 1 (2017) } & \multicolumn{2}{|c|}{ Temporada 2 (2019) } & \multicolumn{2}{|c|}{ Temporada 3 (2020) } \\
\hline Título & Duración & Título & Duración & Título & Duración \\
\hline 1. Secretos & 52 & 1. Principios y finales & $54^{\prime}$ & 1. Déjà vu & 62 \\
\hline 2. Mentiras & $45^{\prime}$ & 2. Materia oscura & $55^{\prime}$ & 2. Los supervivientes & $60^{\prime}$ \\
\hline 3. Pasado y presente & $46^{\prime}$ & 3. Fantasmas & $56^{\prime}$ & 3. Adam y Eva & $57^{\prime}$ \\
\hline 4. Vidas dobles & $48^{\prime}$ & 4. Los viajeros & $61^{\prime}$ & 4. El origen & $64^{\prime}$ \\
\hline 5. Verdades & $46^{\prime}$ & 5. Perder y encontrar & $56^{\prime}$ & 5. Vida y muerte & $64^{\prime}$ \\
\hline $\begin{array}{l}\text { 6. Sic mundus creatus } \\
\text { est }\end{array}$ & $51^{\prime}$ & 6. Un ciclo infinito & $55^{\prime}$ & 6. Luz y sombra & $59^{\prime}$ \\
\hline 7. Encrucijadas & $52^{\prime}$ & 7. El diablo blanco & 58 & 7. Tiempo intermedio & $69^{\prime}$ \\
\hline $\begin{array}{l}\text { 8. Lo que se siembra } \\
\text { eso mismo se cosecha }\end{array}$ & 50 & 8. Finales y principios & 58 & 8. El paraíso & $73^{\prime}$ \\
\hline 9. Todo ocurre ahora & $55^{\prime}$ & & & & \\
\hline 10. Alfa y omega & $57^{\prime}$ & & & & \\
\hline
\end{tabular}

Fuente: elaboración propia a partir de la información recogida en el sitio oficial de Dark en Netflix España (https://bit.ly/3eFuYL9)

A través de una cuidada y elaborada trama argumental se van mezclando personajes y localizaciones a lo largo de diferentes momentos en el tiempo (1921, 1953, 1954, 1987, 2019 y 2053), lo que exige al espectador una gran atención para no perderse en la historia. La complejidad narrativa va en aumento con cada temporada, de manera que a medida que se abren otras líneas temporales aparecen nuevos actores que interpretan a un mismo personaje en sus diferentes etapas generacionales -joven, adulta y anciana- e incluso nuevos personajes secundarios. Precisamente este es uno de los aspectos más llamativos de esta ficción para la cual se llevó a cabo un exhaustivo casting que dio como resultado un asombroso parecido entre los actores que interpretaban a un mismo personaje (Figura 1).

Figura 1. El "personaje desconocido", en sus versiones joven, adulta y anciana.

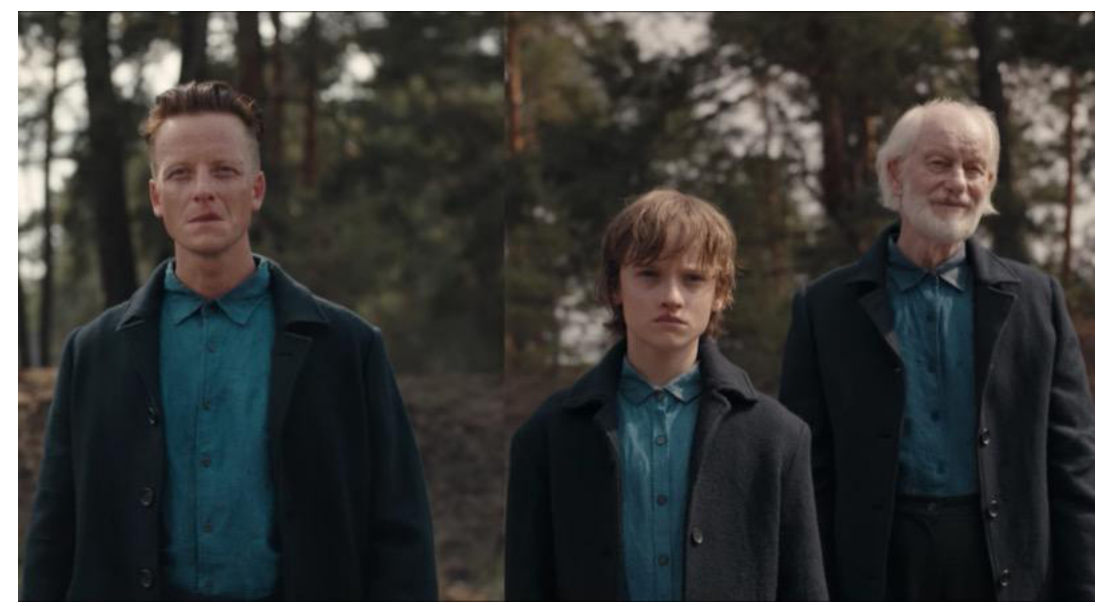

Fuente: captura de pantalla del capítulo 6, Luz y sombra, de la tercera temporada. 
Como sucede con el resto de contenidos de su catálogo, Netflix contempla un espacio en su plataforma dedicado a la serie (https://bit.ly/2IDdqSC) que alberga los capítulos completos de la ficción, así como diferentes contenidos adicionales sobre Dark (tráileres, resúmenes de temporada o sinopsis). Aunque no es posible conocer los datos exactos de audiencia, se puede constatar el surgimiento de una potente comunidad de seguidores en torno a la ficción en sus perfiles oficiales en redes sociales: Facebook (@DARKNetflix), con 1.305.606 seguidores; Twitter (@DarkNetflixDE), con 67.899 seguidores; Instagram (@darknetflix), con 1.197.452 seguidores; y Reddit (r/Dark), con 158.957 miembros. Estos datos se han consultado en marzo de 2021, por lo que están sujetos a variaciones.

En junio de 2020, poco antes del estreno de la tercera entrega de la ficción, Netflix lanzó Dark.Netflix que proporciona a sus seguidores otro tipo de contenido digital e interactivo relacionado con la serie sobre las conexiones familiares existentes entre los personajes y la trama argumental.

\subsection{El concepto de amplificación en la ficcionalidad transmedia}

El escenario en el que se desarrollan actualmente las historias ficcionales está ligado a las potencialidades que ofrece el escenario digital, al poner en juego elementos que antes no se contemplaban, como son las posibilidades de participación de sus seguidores. A la hora de referirse a estas narraciones es necesario introducir el concepto de transmedia, apuntado hace años por Jenkins (2003), que se encuentra en constante evolución a medida que surgen nuevas creaciones audiovisuales (Rodríguez, Paíno y Jiménez, 2016; Scolari, 2013; Villa-Montoya y Montoya-Bermúdez, 2020). Uno de los aspectos principales que caracteriza a este tipo de narraciones es la expansión del universo narrativo a través de distintos soportes y medios, y las diferentes vinculaciones que pueden darse si se tiene en cuenta la participación de los usuarios dentro de la denominada narración base. Como sostienen Molpeceres y Rodríguez, lo verdaderamente novedoso que introduce el transmedia, es el hecho de que "el receptor pueda aportar su parte a la historia, su propio discurso" (2014: 36).

En relación a la investigación sobre la narración transmedia existen numerosos estudios que se centran en la relación entre los medios y la narrativa; pero son menos los análisis que se ocupan de la construcción de mundos dentro de las narrativas transmediales. En este sentido, Rosendo señala que "es necesario entonces elaborar modelos de análisis que permitan examinar cómo se transfieren los elementos que constituyen los mundos transmediales de una forma detallada, más allá de elementos constitutivos generales" (2016: 67).

Los estudios sobre narrativas transmediales se ocupan generalmente de la relación entre los medios y la narrativa, con resultados cada vez más interesantes (cf. García \& Heredero 2015) pero no por el transmedial world-building (Maj 2015) o la construcción de mundos dentro de las narrativas transmediales. Es necesario entonces elaborar modelos de análisis que permitan examinar cómo se transfieren los elementos que constituyen los mundos transmediales de una forma detallada, más allá de elementos constitutivos generales.

Esta expansión narrativa ha propiciado diferentes discusiones académicas y, entre ellas, se encuentra la aportada por Pearson (2020). Dicha autora sugiere utilizar el término de ampliación, frente al de expansión, y lo fundamenta en dos razones:

En primer lugar, el término «ampliación» no implica necesariamente una expansión narrativamente significativa, esto es, una que extienda o reinterprete elementos, como los acontecimientos o personajes, previamente establecidos. (...) En segundo lugar, la expansión parece implicar implícitamente una cohesión mientras que la ampliación no lo hace; una ampliación puede tener puntos de contacto mínimos con la transficción previamente establecida. Los textos añadidos como ampliaciones, a diferencia de los episódicos, no implican continuidad narrativa. (Pearson, 2020: 25-26) 
Estas cuestiones entroncan directamente con las aportaciones de Thon (2015), autor que se nutre de los trabajos previos de Jenkins (2011), Wolf (2012) y Ryan (2008), y continúa avanzado dentro de esta literatura científica. Concretamente, define las funciones que pueden cumplir dos obras narrativas individuales dentro de un contenido transmedia. Para ello hace alusión a tres conceptos: redundancia, expansión o modificación, que se diferencian entre sí en la cantidad de información nueva que se aporta con respecto a la narración base.

I would like to suggest that two single narrative works within a transmedial entertainment franchise can be defined, first, by a relation of redundancy, when one is aiming to represent the same elements of a storyworld that the other represents; second, by a relation of expansion, when one is aiming to represent the same storyworld that the other represents but adds previously unrepresented elements; and, third, by a relation of modification, when one is aiming to represent elements of the storyworld represented by the other but adds previously unrepresented elements that make it impossible to comprehend what is represented as part of a single, non contradictory storyworld. (Thon, 2015: 33)

Partiendo de las aportaciones de estos dos autores se propone para abordar el objeto de estudio de esta investigación la utilización terminológica de amplificación redundante, expansiva y modifica$d a$, frente al simple concepto de expansión narrativa, al considerar que dicho término implica una lectura más amplia del fenómeno desde la perspectiva de aportaciones nuevas al relato base.

Además, se parte de la concepción terminológica de transficcionalidad acuñada por Marie-Laure Ryan, entendida como "the migration of fictional entities across different texts" (2013: 383) dentro del contexto que marca la narración transmedia, donde tradicionalmente se ha venido utilizado el concepto de universo narrativo.

\section{Marco metodológico}

La revisión de la literatura existente relacionada con la serie Dark permite corroborar el interés que ha suscitado este objeto de estudio desde diferentes perspectivas académicas (Albert, 2020; Fronza, 2019; Júnior, 2020; Paladines, 2018; Valenzuela, 2018; Vargas y Corrêa, 2019). La mayoría de estos trabajos científicos se ha centrado en cuestiones filosóficas y literarias vinculadas a la concepción espacio-temporal que plantea la ficción, así como en el análisis del contenido en sí mismo de la serie, desde el punto de vista cinematográfico. Ahora bien, a diferencia de estos estudios previos, la presente investigación propone un enfoque novedoso al profundizar en las potencialidades narrativas interactivas que ofrece la plataforma digital de la serie Dark a sus usuarios/seguidores. Para abordar este análisis se parte de las siguientes preguntas:

1. ¿Qué proporciona la plataforma digital Dark.Netflix a los usuarios/seguidores, a diferencia de la serie tradicional, desde el punto de vista narrativo?

2. ¿La amplificación de la historia a través de la plataforma Dark.Netflix constituye una estrategia de transficcionalidad transmedia?

3. ¿Qué relación se establece entre el usuario/seguidor y la plataforma Dark.Netflix?

Para dar respuesta a estas preguntas se proponen los siguientes objetivos de investigación:

1. Analizar las potencialidades que ofrece la plataforma digital Dark.Netflix desde el punto de vista narrativo, teniendo como referencia la serie audiovisual Dark.

2. Identificar cómo vendría definida la amplificación de la historia en la plataforma digital Dark.Netflix.

3. Determinar en qué medida la plataforma Dark.Netflix puede considerarse como una estrategia de transficcionalidad transmedia. 


\subsection{Método de análisis}

A la hora de abordar el objeto de estudio planteado se ha optado, desde el punto de vista metodológico, por el empleo del estudio de caso y la técnica del découpage interactivo. Concretamente, el estudio de caso (Yin, 2003; 2004) se centra en la plataforma Dark.Netflix cuyos contenidos están vinculados a la serie de ficción original del mismo nombre. Esta técnica metodológica se complementa con el uso del découpage interactivo, propuesta por Freixa, Soler-Adillon, Sora e Ignasi (2004) que la definen como:

un sistema de análisis formal de audiovisuales interactivos que permite establecer una observación detallada de los aspectos que conforman cualquier audiovisual interactivo: la estructura que lo sustenta, los contenidos, las interfaces a través de las cuales se accede al mismo y los diálogos de interacción que propone (Freixa, Soler-Adillon, Sora e Ignasi, 2014: 1).

El análisis de la plataforma digital e interactiva de la serie Dark ha sido realizado tras el estreno de la tercera y última temporada de la ficción, en 2020. Para ello se han contemplado dos fases de análisis: una primera más descriptiva, destinada a ofrecer los datos identificativos de la plataforma digital; y una segunda, que ha abordado en profundidad el análisis de cuatro variables principales: contenido, estructura, interfaz e interacción de la plataforma objeto de estudio.

De este modo, desde el punto de vista metodológico, se establece una relación directa entre los contenidos teóricos que hacen alusión a las diferentes formas en las que se puede materializar la amplificación en una transficción transmedia (redundancia, expansión o modificación) y la identificación de las mismas a través del análisis de las variables propuestas desde técnica del découpage interactivo, para abordar los objetivos propuestos (Tabla 2).

Tabla 2. Elementos para definir la estrategia de amplificación

\begin{tabular}{|l|l|}
\hline Modalidades de amplificación & Elementos identificativos de la estrategia de amplificación en Dark.Netflix \\
\hline Amplificación redundante & Elementos que están tanto en la ficción como en la plataforma Dark.Netflix. \\
\hline Amplificación expansiva & $\begin{array}{l}\text { Elementos que están presentes tanto en la ficción como en la plataforma } \\
\text { Dark.Netflix, pero añadiendo además otros nuevos. }\end{array}$ \\
\hline Amplificación modificada & $\begin{array}{l}\text { Elementos que están presentes en la plataforma Dark.Netflix y que no apare- } \\
\text { cen representados en la ficción. }\end{array}$ \\
\hline
\end{tabular}

Fuente: elaboración propia partiendo de las aportaciones teóricas de Pearson (2020) y Thon (2015)

\section{Análisis y resultados}

En los siguientes epígrafes se recogen los principales hallazgos de este estudio.

\subsection{La plataforma digital interactiva Dark.Netflix}

La plataforma objeto de estudio, denominada por sus creadores como The Official Guide o la Experiencia, nace con el objetivo de ayudar a los seguidores de la ficción a comprender la trama que se desarrolla en la serie, desde el punto de vista del espacio, el tiempo y las relaciones entre los personajes. Se trata de un producto independiente y de acceso gratuito que dispone de su propia URL (https://dark.netflix.io/), ajena al espacio dedicado a la misma dentro de la web de Netflix, por lo que no precisa suscripción.

Está diseñada teniendo en cuenta las características del soporte, es decir, introduciendo elementos multimedia, hipertextuales e interactivos que permiten llevar a cabo la experiencia del usuario. Una 
de las principales particularidades que ofrece esta plataforma es la posibilidad de elegir entre ocho idiomas, abriendo una mayor pluralidad lingüística que la ofrecida en la serie.

\subsection{El puzle narrativo de la plataforma Dark.Netflix}

La plataforma mantiene la misma estética de la serie, caracterizada por una atmósfera oscura que recuerda al género del cine negro. Este tenebrismo estético, que estará presente en toda la experiencia, se puede observar desde el inicio, en la animación de entrada a la plataforma -de apenas unos segundos de duración- en la que aparece el símbolo del infinito, seguido del título Dark con la misma tipografía empleada en la cabecera de la serie.

Una vez dentro, el usuario se encuentra ante un menú de selección con forma de triqueta, que constituye la puerta de acceso al contenido. Cada uno de los óvalos de esta figura se vincula con una temporada de la serie. Se trata de un recurso simbólico, recurrente en la trama, que se asocia con algunos elementos clave de la ficción: las cuevas de Winden que utilizan los viajeros para desplazarse por el tiempo, el cuaderno de cuero que recoge toda la información sobre estos viajes y en las notas de la versión adulta de Jonas. Estos elementos son los que desencadenan las diferentes tramas narrativas de la serie dando vida a la historia. En lo que respecta a Dark.Netflix, la mencionada triqueta alcanza una nueva dimensión desde el punto de vista iconológico; es decir, mientras que en la ficción seriada adquiere un significado importante para los "viajeros del tiempo", en la plataforma interactiva lo tendrá para los usuarios. En este sentido, la triqueta actuará como "guía" indicando al usuario en qué línea temporal se encuentra en cada momento.

Para poder acceder a los contenidos, el usuario debe seleccionar en esta figura la temporada y, desde la barra horizontal que aparece bajo ella, el capítulo que desee (del 1 al 8, o del 1 al 10, en función de la temporada), como se puede observar en la figura 2.

Figura 2. Home de la plataforma Dark.Netflix

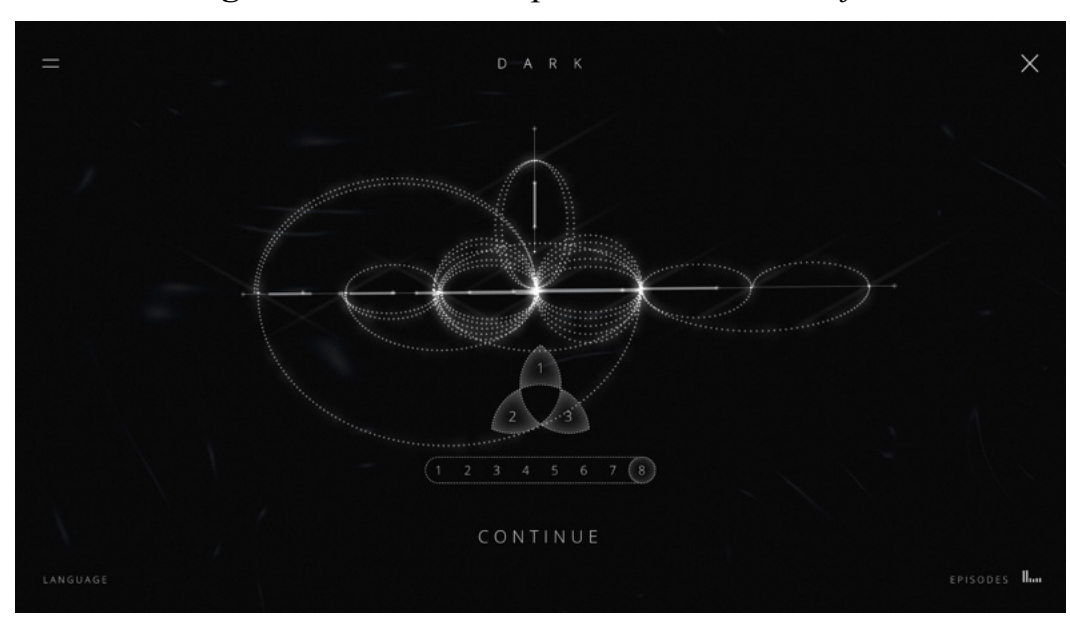

Fuente: captura de pantalla de la plataforma.

En función de los episodios seleccionados, en la parte central de la pantalla comenzará a dibujarse una nueva triqueta en la que las líneas sólidas representan el tiempo y las de puntos indican los diferentes viajes temporales que realizan los personajes en el conjunto de episodios seleccionados. En este sentido, a medida que el usuario se aproxima al último episodio, este elemento aparecerá más completo.

Lo más importante que hay detrás de esta estructuración de los contenidos es que su diseño se ha ideado de tal modo que, si el usuario no lo decide previamente, no accederá a contenidos que no 
haya consumido en la ficción. En definitiva, la triqueta podría considerarse el recurso visual e interactivo que desencadena y vehicula la narración digital que plantea esta plataforma y, por lo tanto, el que propone una nueva experiencia narrativa de Dark al usuario. Además, dicho elemento narrativo permite profundizar en la versión de transficcionalidad que abre la plataforma objeto de estudio en relación a la serie.

Una vez que el usuario ha seleccionado la temporada y los episodios, y acciona el botón "Continuar”, aparece un árbol genealógico con las fotografías de los personajes de la serie (Figura 3). La cantidad de personajes representados en él dependerá nuevamente de los capítulos seleccionados.

Figura 3. Árbol genealógico de los personajes de la serie

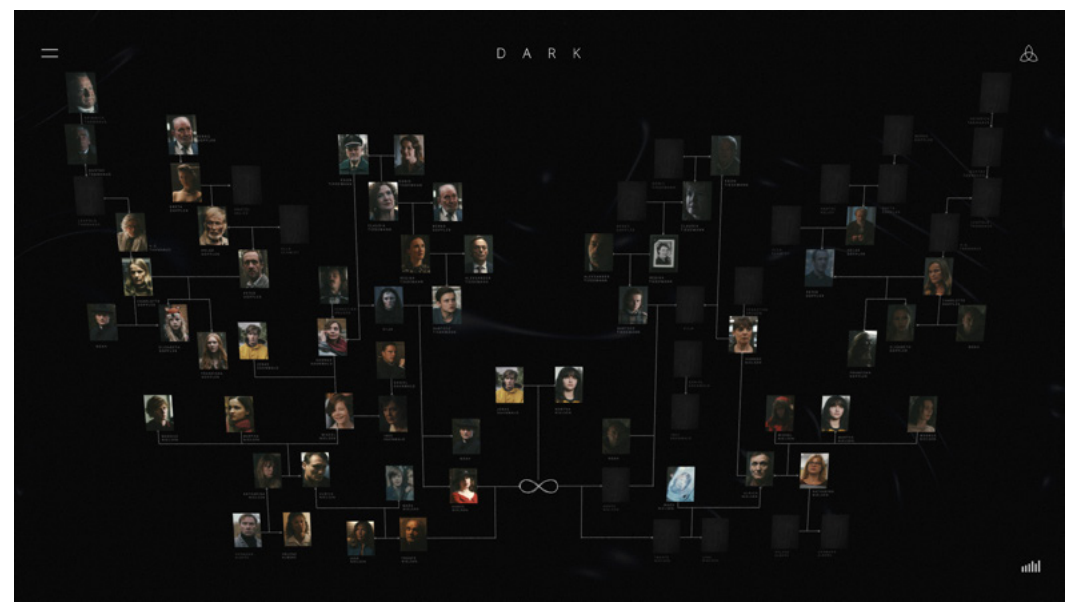

Fuente: captura de pantalla de la plataforma.

Cada una de estas fotografías incluye un hiperenlace, de manera que al pulsar sobre ella se abre una nueva página con toda la información sobre el personaje seleccionado. Este árbol genealógico es el elemento narrativo utilizado en Dark.Netflix para materializar la transficcionalidad de la serie. Es decir, el usuario ya no está condicionado a seguir la trama de la forma habitual -a través de los diferentes episodios y temporadas-, sino que puede acceder a los contenidos que desea consumir a través de la interacción que presentan los personajes, dando lugar con ello a una nueva "versión" de la historia.

Otra dimensión de esta transficcionalidad se encuentra plasmada en el menú de selección, ubicado en la parte superior izquierda de la plataforma, que permite al usuario acceder a información relacionada con el "quién", "qué" y "cuándo", vinculados con la narración base (serie). Se detalla, a continuación, cada uno de ellos:

1. Quién: recoge nuevamente las fotografías de los personajes principales que aparecen en la ficción. Son las mismas que se encuentran en el árbol genealógico y, al pulsar sobre ellas, se accede a la misma información. En concreto, estas imágenes son capturas extraídas de la propia serie.

2. Qué: incluye referencias a 40 objetos y lugares destacados de la ficción, como el búnker, la caravana de Bernadette, la carta de despedida de Michael, las cuevas de Winden, la estación de policía, la moneda de un centavo, la planta nuclear o la partícula de Dios, entre otros.

3. Cuándo: en este apartado se incluyen los diferentes años en los que transcurre la trama. Concretamente, 1888, 1920/21, 1953/54, 1986/87, 2019, 2019/2020, 2020 (posapocalipsis), 2052 y $2052 / 53$. 
Completan este menú cuatro botones de acceso a:

4. Familias: redirige al usuario al árbol genealógico.

5. Idioma: permite modificar el idioma de la plataforma.

6. Episodios: recoge una breve sinopsis de cada uno de los capítulos de las tres temporadas de la ficción televisiva. Incluye una captura de cada episodio, pero no permite acceder a la visualización del mismo.

7. Compartir: permite compartir la URL de la plataforma en Facebook, Twitter o WhatsApp, o simplemente copiar el enlace.

En todo momento, la experiencia está acompañada de una música que recuerda a la banda sonora de la ficción, así como de otros efectos de sonido a medida que el usuario navega por la plataforma. Este recurso extradiegético genera un clima de suspense que apoya en todo momento a la narración interactiva. Se puede activar y desactivar a través del botón situado en la parte inferior derecha de la pantalla.

La estructura y la interfaz, en las que se ha profundizado en este epígrafe, son los elementos que componen la plataforma objeto de estudio y articulan el puzle narrativo de la ficción interactiva de Dark.

\subsection{La estrategia de amplificación de la serie Dark}

Dark.Netflix utiliza como elemento narrativo recursos fotográficos que proceden de clips de la propia serie. Por este motivo, predominan las imágenes con contraluces y tonos poco saturados. Es significativa la ausencia total de vídeo en la plataforma, aspecto que la diferencia del espacio dedicado a la serie en Netflix, donde este recurso es el protagonista (bien en los capítulos completos de la ficción seriada, como en los contenidos adicionales de la misma). Teniendo en cuenta que las fotografías identificadas en Dark.Netflix pertenecen a la narración lineal y episódica de la serie, se puede identificar un tipo de amplificación redundante.

Desde el punto de vista formal, una de las características que definen a estas imágenes es el uso del efecto caleidoscópico, aplicado a un tipo de plano muy corto del rostro de los personajes que miran a cámara (Figura 4). Esto coincide con la cabecera de la serie, donde aparece también el mismo recurso visual por el que una misma imagen parece desdoblarse en varias partes produciendo una ilusión óptica. Dicho efecto se encuentra vinculado directamente a la trama de la serie donde los personajes se muestran en varias dimensiones espacio-temporales.

Figura 4. Efecto caleidoscópico en uno de los personajes de la ficción

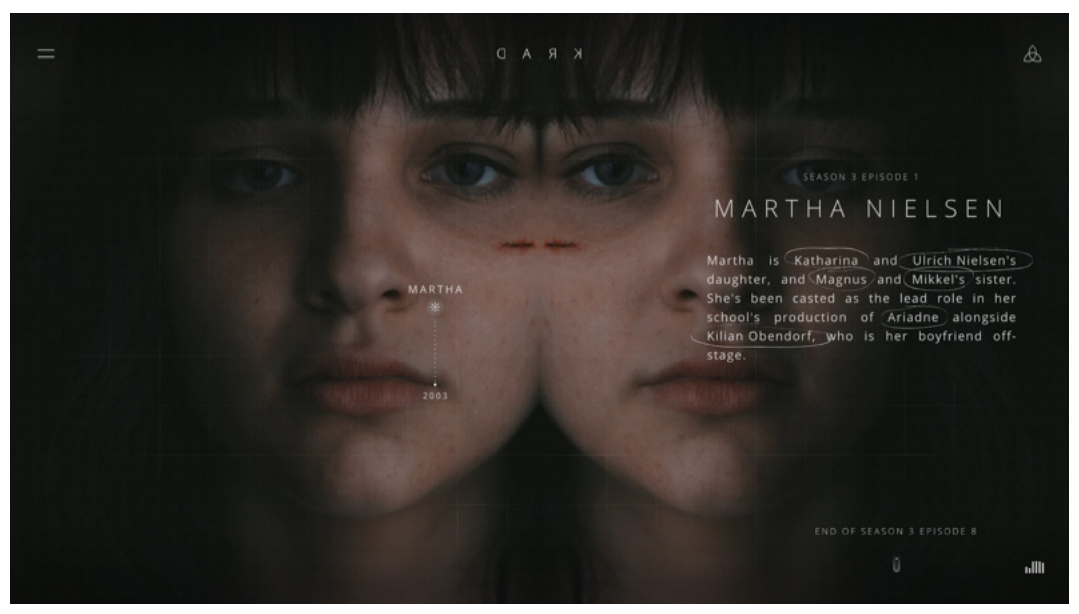

Fuente: captura de pantalla de la plataforma. 
Estas imágenes caleidoscópicas se encuentran a medio camino entre la amplificación redundante y la amplificación expansiva al utilizar elementos que se han visto previamente en la serie, pero incorporando un efecto visual-creativo. En este caso, se propone hablar de amplificación redundante creativa. Esto hace que el espectador pueda estar frente a contenidos nuevos que no se han representado previamente en la historia base (serie) cambiando su percepción.

Otro recurso narrativo muy utilizado en Dark.Netflix es el texto, que acompaña y complementa a las imágenes. Este aparece asociado a un personaje, lugar o tiempo determinado. Teniendo en cuenta la gama cromática de la plataforma, con un claro predominio del color negro, se utiliza una tipografía blanca en todos los casos. A diferencia del caso anterior, dichos recursos textuales sí cumplirían una función de expansión. Ahora bien, este contenido no es completamente novedoso, sino que está vinculado a las tramas narrativas de la serie. Por este motivo, en esta investigación se prefiere hablar de un tipo de amplificación expansiva conectiva -respecto a la utilización del texto-, que podría ser entendida como aquella que aporta unión entre los diferentes personajes, espacio y tiempo que nutren la complicada trama narrativa de la serie.

\subsection{El diálogo interactivo de la plataforma Dark.Netflix}

Los hipertextos utilizados en Dark.Netflix rompen la conexión lineal y ayudan a extender la narración a través del acceso a las conexiones que se producen entre personajes (quién), acontecimientos (qué) y escenarios (cuándo), desde el punto de vista interactivo. Estos hipertextos se encuentran en cada uno de los textos que acompañan a las fotografías (aparecen indicados en algunas palabras clave, con un círculo) y su principal característica radica en que ofrece al usuario, una narración sin principio ni final. Este hecho no responde a una simple estructura de información en nodos, sino que podría considerarse como un metarrelato de Dark, aspecto que coincide con el propio argumento de la serie. Por esta razón, en la plataforma Dark.Netflix sería más correcto utilizar el término de transficcionalidad interactiva puesto que son los hipertextos los que permiten acceder a otros universos narrativos y abren un tipo de diálogo interactivo a los usuarios. Esto vendría condicionado por la temporada y capítulos seleccionados, de tal modo que, a mayor número de temporadas y capítulos, mayor diálogo con la narración interactiva creada por los autores de Dark.Netflix.

Teniendo en cuenta que las tramas narrativas de la serie juegan en todo momento con los saltos temporales en la narración base de la ficción, la plataforma plantea un doble diálogo. Concretamente, al acceder a un personaje, objeto o lugar, el usuario puede seguir la trama de manera cronológica (utilizando el scroll). Esto marca una diferencia con respecto a la ficción seriada, donde los saltos temporales dependen de los capítulos en serie, los cuales contemplan simultáneamente tramas desarrolladas en varias líneas temporales. Por otra parte, el usuario puede optar por pasar por alto la estructura cronológica fijada y realizar sus propias conexiones narrativas con otros personajes, elementos o tiempos (mediante los hipertextos). Dicha interactividad, que termina transformándose en diálogo entre los contenidos y los usuarios, plasma la denominada experiencia interactiva con este producto lanzado por Netflix para los seguidores de su serie Dark, que eligen la historia dentro de la historia (metarrelato) que quieren consumir.

\section{Discusión y conclusiones}

El análisis realizado permite retomar aquí las preguntas de las que partía este estudio. En relación a la primera, los resultados permiten afirmar que Dark.Netflix, a diferencia de la ficción seriada, ofrece a los usuarios/seguidores una forma alternativa de consumir la historia. La serie tiene una estructura narrativa clásica, en la que los diferentes tiempos narrativos son cohesionados a través de sus personajes. El tiempo narrativo lo vehiculan las acciones de los personajes en los diferentes tiempos diegéticos -presente, pasado y futuro-. En la plataforma aparece una estructura narrativa in- 
teractiva de manera que, a diferencia de la serie, el usuario puede manipular el concepto del tiempo diegético que está unida a los diferentes momentos temporales y a la acción de los personajes en ese momento, a través de los hipertextos. Esto se produce a través de una estructura narrativa de metarrelato, el cual se materializa a través de las diferentes conexiones que proporcionan los elementos interactivos/hipertextos.

En cuanto a la segunda pregunta de investigación ligada al concepto de amplificación, se puede afirmar que Dark.Netflix constituye una estrategia de transficcionalidad transmedia. La razón de ello se encuentra en que la plataforma ofrece una amplificación de redundancia creativa y de expansión conectiva, lo que permite hablar de la citada transficcionalidad. Es decir, el usuario accede a la misma historia que ha consumido en la serie, pero narrada de diferente forma, a partir de las conexiones cronológicas (personajes y acontecimientos) y, además, puede construir su propio guión -en este caso interactivo-, de la historia modificada que va a consumir en la plataforma. Este hecho materializa la denominada experiencia de usuario, convirtiéndose esta en el principal elemento diferenciador que proporciona Dark.Netflix a sus seguidores en relación al resto de contenidos que constituyen la estrategia transmedia de la serie.

Este aspecto enlaza con la última de las preguntas planteadas en esta investigación que alude a la relación que se establece entre el usuario/seguidor y la plataforma, que no es otra que el diálogo que esta genera entre creadores, usuario y contenido. A este respecto, la principal particularidad que presenta dicho diálogo es que está condicionado a los elementos narrativos interactivos que contempla Dark.Netflix; es decir, las conexiones que ofrecen desde el punto de vista espacio-temporal vehiculan ahora las tramas a elección del usuario y que están vinculadas a los personajes de la narración base.

Es especialmente significativo que, tras el análisis realizado, no se han identificado elementos que permitan hablar de una amplificación modificada dentro de Dark.Netflix. Esto se debe, principalmente, a que el usuario no tiene la posibilidad de aportar contenidos nuevos a la narración. Resultaría especialmente innovador en este sentido la incorporación de un apartado de participación específico donde los seguidores de la ficción pudieran compartir sus contenidos originales, como así ocurre en otros proyectos como Las Sinsombrero (https://bit.ly/2Tp05TA) o Lo que hicimos fue secreto (https://bit.ly/2TqRmAl), que analiza la influencia de las subculturas punk y hardcore en la configuración social de la ciudad de Madrid.

El análisis realizado abre nuevas líneas de investigación en torno a las potencialidades narrativas (creador, usuario y contenido) que proponen las plataformas digitales vinculadas a las series de ficción, todo ello dentro del contexto que delimita la narración transmedia. Asimismo, este estudio deja abierta la posibilidad de establecer estudios comparativos con otras experiencias transficcionales utilizando los mismos presupuestos metodológicos aquí aportados.

\section{Bibliografía}

Albert, M. V. (2020). Dark: Todo está extrañamente conectado. Cameraman: Revista técnica cinematográfica, 107, 18-25. https://bit.ly/354JozO

Alcolea, G. (2017). Convergencia del audiovisual e Internet: el modelo webcasting en Atresmedia. En J. A. González Alba (Ed.), Tendencias e innovación en la empresa periodística (pp. 56-72). Egregius.

Amaya, J. \& Charlois, A. (2017). Memoria cultural y ficción audiovisual en la era de la televisión en streaming. Una exploración en torno a la serie Narcos como relato de memoria transnacional. Comunicación y Sociedad, 31(enero-abril), 15-44. https://doi.org/10.32870/cys.v0i31.6852 
Barnwell, J. (2020). How does the design of the Byers' home in Stranger Things (2016-2019 Netflix) reflect notions of nostalgia for a particular space in time? En Investigating Stranger Things: Upside Down in the World of Mainstream Cult Entertainment. Palgrave Macmillan.

Billard, T. J. (2019). Experimental Evidence for Differences in the Prosocial Effects of BingeWatched Versus Appointment-Viewed Television Programs. Journalism \& Mass Communication Quarterly, 96(4), 1025-1051. https://doi.org/10.1177/1077699019843856

Capapé, E. (2020). Nuevas formas de consumo de los contenidos televisivos en España: una revisión histórica (2006-2019). Estudios sobre el Mensaje Periodístico, 26(2), 451-459. https:// doi.org/10.5209/esmp.67733

Carrillo, J. (2018). Paradigma Netflix. El entretenimiento de algoritmo. Editorial UOC.

Carvalho, G., Barcelos, T. \& Dias, E. (2017). Estranhar os algoritmos: Stranger Things e os públicos de Netflix. Revista GEMInIS, 8(1), 38-59. https://bit.ly/3lbHMdh

Castro, D., Rigby, J.M., Cabral, D. \& Nisi, V. (2019). El viaje del observador compulsivo: investigación de motivaciones, contextos y estados afectivos que rodean la visualización de Netflix. Convergencia, 1-18. https://doi.org/10.1177/1354856519890856

DeCarvalho, L. J. \& Cox, N. B. (2016). Extended "Visiting Hours": Deconstructing Identity in Netflix's Promotional Campaigns for Orange Is the New Black. Television \& New Media, 17(6), 504-519. https://doi.org/10.1177/1527476416647495

Elnahla, N. (2020). Black Mirror: Bandersnatch and how Netflix manipulates us, the new gods. Consumption Markets \& Culture, 23(5), 506-511. https://doi.org/10.1080/10253866.2019.1653288

Ellingsen, S. (2014). Seismic Shifts: Platforms, Content Creators and Spreadable Media. Media International Australia, 150(1), 106-113. https://doi.org/10.1177/1329878X1415000121

Freixa, P., Soler-Adillon, J., Sora, C. \& Ignasi, J. (2014). Aportaciones del découpage interactivo en la lectura y análisis de audiovisuales interactivos de los cibermedios. Hipertext.net, 12, 1-15. https://doi.org/10.2436/20.8050.01.1

Fronza, M. (2019). A websérie Dark como artefato da cultura histórica: a estrutura de sentimento dos jovens relacionada aos conflitos sociais e ambientais na perspectiva da ficção científica.

Caminhos da Educação: diálogos, culturas e diversidades, 1(3), 6-25. https://doi.org/10.26694/ caedu.v1i3.9636

González-Neira, A. \& Fernández-Martínez, L. M. (2019). Nuevos hábitos de consumo televisivo: retos de la audiencia en diferido. Index.comunicación, 9(3), 75-92. https://bit.ly/3jYTWoz

Goudmand, A. (2020). Le découpage chapitral dans House of Cards : une stratégie narrative liée au modèle de diffusion de Netflix. Itinéraires, 1-17. https://doi.org/10.4000/itineraires.7673

Heredia, V. (2016). Revolución Netflix: desafíos para la industria audiovisual. Chasqui. Revista Latinoamericana de Comunicación, 135, 275-295. https://bit.ly/2I7QsTm

Hidalgo, T. (2020). Netflix como productor audiovisual. Obra Digital, 19, 117-132. https://doi. org/10.25029/od.2020.272.19

Hills, M. (2020). Black Mirror as a Netflix Original. En M. Hilmes, M. Hills y R. Pearson (Eds). Transatlantic Television Drama: Industries, Programs, and Fans. https://doi.org/10.1093/ oso/9780190663124.003.0014 
Jenkins, H. (2003, 15 de enero). Transmedia Storytelling: Moving characters from books to films to video games can make them stronger and more compelling. MIT Technology Review. https://bit. ly/321QdeK

Jenkins, H. (2008). La cultura de la convergencia de los medios de comunicación. Editorial Paidós.

Jenkins, H. (2011, 1 de agosto). Transmedia 202: Further Reflections. Confessions of an Aca-Fan. Recuperado de https://bit.ly/2W7X4bp

Júnior, S. J. S. (2020). A experiência logopática dos conceitos na complexidade narrativa da série Dark. Brazilian Journal of Development, 6(7), 46908-46916. https://doi.org/10.34117/bjdv6n7-359

Lad A., Butala S. \& Bide P. (2020) A Comparative Analysis of Over-the-Top Platforms: Amazon Prime Video and Netflix. En Bansal J., Gupta M., Sharma H. \& Agarwal B. (Eds.) Communication and Intelligent Systems. ICCIS 2019. Lecture Notes in Networks and Systems, vol. 120. Singapur: Springer. https://doi.org/10.1007/978-981-15-3325-9_22

Lobato, R. (2019). Netflix Nations. The Geography of Digital Distribution. University Press.

Matisse, N. (2013). House of Cards: The '13-Hour Movie' Defining the Netflix Experience. Arstechnica. https://bit.ly/2GAHVrN

Matrix, S. (2014). The Netflix Effect: Teens, Binge Watching, and On-Demand Digital Media Trends. Jeunesse: Young People, Texts, Cultures, 6(1), 119-138. https://doi.org/10.1353/jeu.2014.0002

Mayorga, S. (2019). Netflix, estrategia y gestión de marca en torno a la relevancia de los contenidos. adComunica, 18, 219-244. https://doi.org/10.6035/2174-0992.2019.18.11

Molpeceres, S. \& Rodríguez, M. I. (2014). La inserción del discurso del receptor en la narrativa transmedia: el ejemplo de las series de televisión de ficción. Historia y Comunicación Social, 19, 31-42. https://doi.org/10.5209/rev_HICS.2014.v19.45008

Naranjo, A. \& Fernández-Ramírez, L. (2020). Cambios en la estructura narrativa de las series de Netflix. El caso de Mindhunter. En R. Álvarez y M. Rajas (Eds.). Paradigmas de la Narrativa Audiovisuales (pp. 137-153). https://www.eumed.net/rev/asri/

Paladines, L. V. (2019). El eterno retorno: análisis de la concepción temporal en la serie Dark de Netflix. Paakat: Revista de Tecnología y Sociedad, 9(16), 1-8. https://doi.org/10.32870/ Pk.a9n16.382

Pearson, R. (2020). Ampliación y cohesión en mundos transficcionales. En García, A. N. \& Ortiz, M. J. (Eds.). Cine y series. La promiscuidad infinita. Comunicación Social Ediciones y Publicaciones.

Raya, I., Sánchez-Labella, I. \& Durán, V. (2018). La construcción de los perfiles adolescentes en las series de Netflix Por trece razones y Atípico. Comunicación y Medios, 37, 131-143. https:// doi.org/10.5354/0719-1529.2018.48631

Rocha, S. M. (2018). Political visuality of Latin America in Narcos: an analysis through the television style. Comunicación y medios, 27(37), 106-118. https://doi.org/10.5354/07191529.2018.48572

Rodríguez, M. I., Paíno, A. \& Jiménez, L. (2016). El soporte multiplataforma como clave de éxito de la Narración Transmedia. Estudio de caso del webdoc "Las Sinsombrero". Icono 14, 14(2), 304-328. https://doi.org/10.7195/ri14.v14i2.967 
Ruiz, F. J. \& Bustos, J. (2020). Opinión pública y nuevas estrategias comunicativas en la industria audiovisual: el caso de Netflix y la serie Sense8. Opinião Pública, 26(2), 377-400. https://doi. org/10.1590/1807-01912020262377

Ryan, M. L. (2008). Transfictionality across Media. En J. Pier \& J. A. García (Eds). Theorizing Narrativity (pp. 385-417). Berlin: De Gruyter.

Scolari, C. (2009). Alrededor de las convergencias. Conversaciones teóricas, divergencias conceptuales y transformaciones del ecosistema de los medios. Signo y Pensamiento, 54(XXVIII), 44-55. http://bit.ly/2hyq07G

Scolari, C. (2013). Narrativas transmedia: Cuando todos los medios cuentan. Deusto.

Smith, A. M. (2015). Orange is the Same White. New Political Science, 37(2), 276-280, https:// doi.org/10.1080/07393148.2014.995401

Susanno, R., Phedra, R. \& Murwani, I. A. (2019). The determinant factors of the intention to spend more time binge-watching for Netflix Subscriber in Jakarta. Journal of Research in Marketing, 10(3), 807-812. https://doi.org/10.17722/JORM.V10I3.270.G102

Thon, J. N. (2015). Converging Worlds: From Transmedial Storyworlds to Transmedial Universes. Storyworlds: A Journal of Narrative Studies, 7(2), 21. https://doi.org/10.5250/ storyworlds.7.2.0021

Valenzuela, S. T. (2018). A série Dark: leituras do espaço-tempo. $41^{\circ}$ Congresso Brasileiro de Ciências da Comunicação. https://bit.ly/2I3oit4

Vargas, H. \& Corrêa, A. M. (2019). Recapitulaçoes na série original Netflix Dark: alteraçoes na estructura narrativa tradicional televisual. Capa, 17(31). https://bit.ly/3eqFd4t

Villa-Montoya, M. \& Montoya-Bermúdez, D. (2020). ¿Transmedia o cross-media? Un análisis multidisciplinar de su uso terminológico en la literatura académica. Co-Herencia, 17(33), 249275. https://doi.org/10.17230/co-herencia.17.33.9

Yin, R. (2003). Case Study Research. Design and Methods. Sage.

Yin, R. (2004). The Case Study Anthology. Sage.

Wolf, M. J. P. (2012). Building Imaginary Worlds: The Theory and History of Subcreation. New York: Routledge.

Wyche, E. (2018, 5 de enero). 'Dark' could be Netflix's biggest European hit so far. Screendaily. Recuperado de https://bit.ly/3Bn8KHo 